\section{The Vacuum-Operated Nutrient Delivery System: Hydroponics for Microgravity}

\author{
Christopher S. Brown ${ }^{1}$, William M. Cox ${ }^{2}$, Thomas W. Dreschel ${ }^{1}$, \\ and Peter V. Chetirkin \\ Kennedy Space Center, FL 32899
}

Additional index words. Phaseolus vulgaris, reduced pressure

Abstract. A nutrient delivery system that may have applicability for growing plants in microgravity is described. The Vacuum-Operated Nutrient Delivery System (VONDS) draws nutrient solution across roots that are under a partial vacuum at $\approx 91 \mathrm{kPa}$. Bean (Phaseolus vulgaris L. cv. Blue Lake 274) plants grown on the VONDS had consistently greater leaf area and higher root, stem, leaf, and pod dry weights than plants grown under nonvacuum control conditions. This study demonstrates the potential applicability of the VONDS for growing plants in microgravity for space biology experimentation and/or crop production.

A major obstacle to devising a system that could support plant growth in the micro-

Received for publication 24 Feb. 1992. Accepted for publication 17 June 1992. Mention of a trademark or proprietary product does not constitute a guarantee or warranty of the product by the Bionetics Corp. or NASA nor does it imply its approval to the exclusion of other products which may be suitable. The cost of publishing this paper was defrayed in part by the payment of page charges. Under postal regulations, this paper therefore must be hereby marked advertisement solely to indicate this fact.

${ }^{1}$ The Bionetics Corp., Mail Code BIO-3.

${ }^{2}$ NASA Biomedical Engineering Office, Mail Code MD-ENG. gravity of space is the design of a water and nutrient delivery subsystem. Any mechanical parts involved must operate reliably in microgravity, and nutrient solution must be confined to the root zone. Several techniques have been suggested, including the use of hydrophilic microporous ceramic tubes (Dreschel and Sager, 1989), acrylic membranes (Wright et al., 1988), and solid substrates such as rock wool (Kitaya et al., 1988), or a combination of porous tubes surrounded by a solid matrix (Morrow et al., 1990). Here we report on an alternative approach in which roots are maintained and supplied with water and nutrients while under partial vacuum. Using our system, called the Vacuum-Op- erated Nutrient Delivery System (VONDS), we were able to grow bean plants through their entire life cycle.

The basic plant-support unit of the VONDS is shown in Fig. 1. A 500-ml polypropylene jar, covered with black tape, was used as the root-containment vessel (RCV). A screw-on lid was modified by cutting an b-cm-diameter hole in the center. A flat PVC disk with a flat O-ring beneath was placed over the container opening and sealed. The flat inner disk contained three openings, one to accommodate nutrient solution input, one for the vacuum/nutrient solution outlet, and one for the plant stem. Both the nutrient input and vacuum lines were black neoprene tubing, $32 \mathrm{~mm}$ o.d. and $16 \mathrm{~mm}$ i.d. Lines were attached to the container with standard luerlock fittings and connected to high-density polypropylene filters of 70 - $\mu \mathrm{m}$ pore size (Porex Technologies, Fairburn, Ga.). The stem fit snugly through a slitted piece of soft, black, closed-cell foam. The foam was held in place by a no. 12 tapered caplug (Protective Closures Co., Buffalo, N.Y.) with a 15mm-diameter hole in the center. The foamcaplug combination was held in place with the screw top and threads from a polypropylene bottle (the diameter of the opening was $25 \mathrm{~mm}$ ).

The nutrient solution (Wheeler et al., 1991) was pumped from a 125 -liter main nutrient solution tank to the nutrient solution manifolds, then returned to the main tank (upper shelf) or a 20-liter sump nutrient tank (lower shelf). Aeration was accomplished through the cascading action of the nutrient solution return to the main tank.. Both nutrient solution manifolds were maintained at $103 \mathrm{kPa}$ 


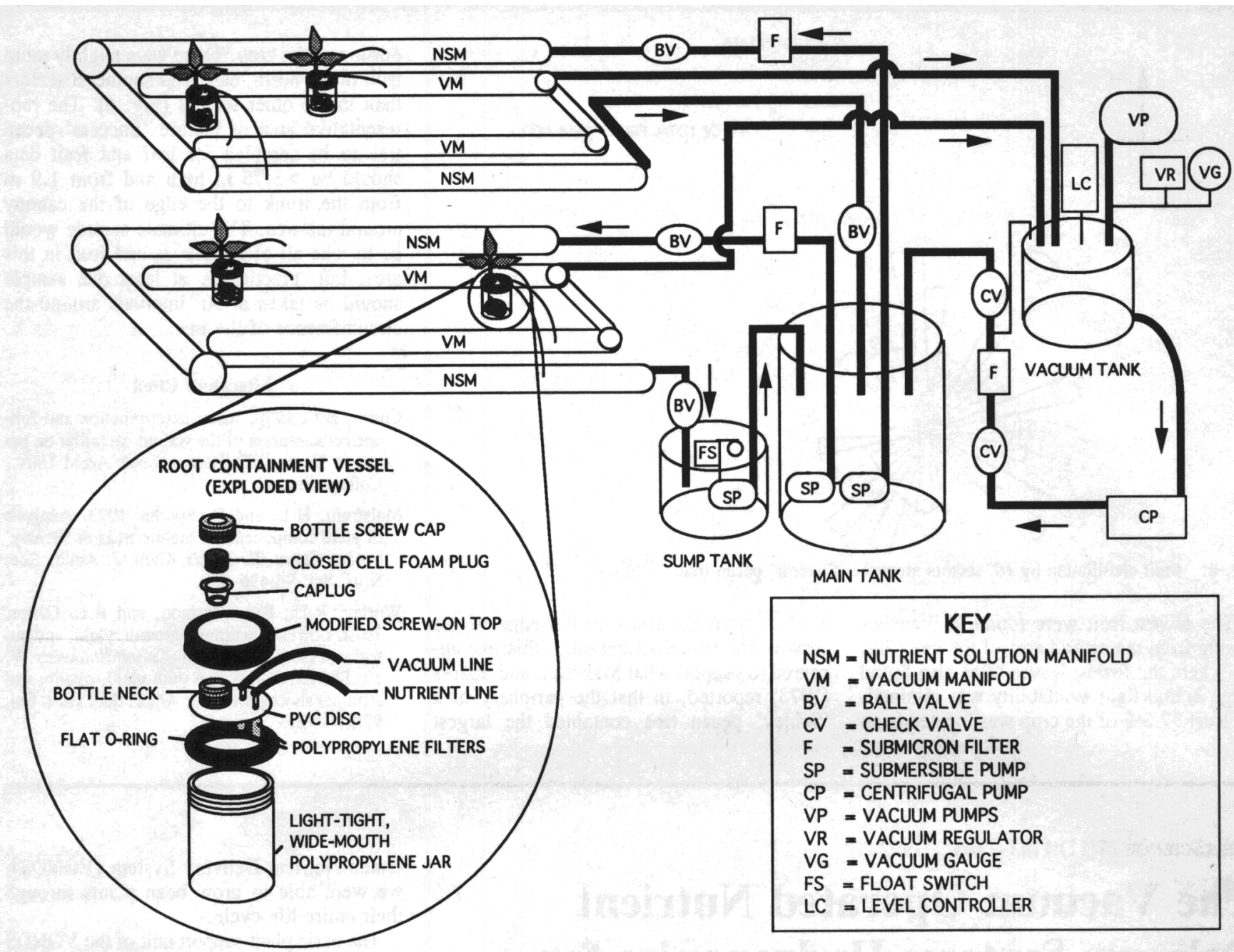

Fig. 1. Schematic diagram of the Vacuum-Operated Nutrient Delivery System root containment vessel and the overall system.

Table 1. Comparison of growth characteristics for 'Blue Lake Bush 274' bean plants grown on the Vacuum-Operated Nutrient Delivery System (VONDS) or under control, nonvacuum conditions.

\begin{tabular}{lccccc}
\hline \hline & \multirow{2}{*}{$\begin{array}{c}\text { Leaf area } \\
\text { Treatment }\end{array}$} & \multicolumn{4}{c}{ Dry wt (g/plant) } \\
\cline { 3 - 6 } & (dm²/plant) & Root & Stem & Leaf & Pod \\
\hline VONDS & $50.8^{* *}$ & $2.44^{*}$ & $4.59^{* *}$ & $12.92^{* *}$ & $18.54^{*}$ \\
Nonvacuum & 30.1 & 1.62 & 2.76 & 7.19 & 11.40 \\
\hline
\end{tabular}

*,**Mean separation within columns significant at $P=0.05$ or 0.01 , respectively.

(for reference, ambient pressure was $101 \mathrm{kPa}$ ). The solution from the lower shelf filled the sump tank and tripped a float switch, turning on a submersible centrifugal pump that returned the solution to the main tank. Neoprene tubing connected the nutrient and vacuum manifolds with the RCV. The nutrient solution flow rate was $52.9 \mathrm{ml} \cdot \mathrm{min}^{-1}$ $( \pm 10.2)$, and the volume of the solution within the RCV was $160 \mathrm{ml}$ with a headspace of $280 \mathrm{ml}$. The solution was drawn from the RCV through the vacuum manifold and into a vacuum tank, both of which were kept at $89 \mathrm{kPa}( \pm 2)$ by two double-headed vacuum pumps. As the vacuum tank filled, it tripped a solution level controller that turned on a second centrifugal pump and returned the solution to the main tank. A partial vacuum at $\approx 89 \mathrm{kPa}( \pm 2)$ was maintained within the RCVs during the entire growing period. The control, nonvacuum RCVs were similar to the VONDS RCVs in that nutrient solu- tion was added via the same mechanism and removed by suction. The only difference was a small hole in the top of the nonvacuum RCVs to dissipate the vacuum and maintain ambient pressure. Demineralized water was added to the main tank to maintain a constant volume, and nutrients were replenished weekly, as needed.

Ten-day-old hydroponically grown seedlings of 'Blue Lake Bush 274' green bean were transplanted into the VONDS and nonvacuum RCVs and placed in a growth chamber that supplied $250 \mu \mathrm{mo} 1 \cdot \mathrm{m}^{-2} \cdot \mathrm{s}^{-1}$ photosynthetically active radiation at the leaf surface from daylight fluorescent lamps. Air was at $28 / 22 \mathrm{C}$ and relative humidity was $60 \%$ / $75 \%$ during the $12 / 12 \mathrm{~h}$ light/dark periods. The nutrient solution was at $25 \mathrm{C}( \pm 1.5)$. Five replicate plants were harvested and measured at 63 days after planting (53 days after transplanting). The data were compared using one-way analysis of variance.
The VONDS was able to adequately support bean plant growth from transplant to final harvest. In fact, at harvest, VONDSgrown plants exhibited significantly greater leaf area and higher root, stem, leaf, and pod dry weights than the control, nonvacuumgrown plants (Table 1).

The ultimate goals in the development of a nutrient delivery system suitable for microgravity are safety, reliability, independence of the need for gravity, and the ability to grow plants as well as can standard, gravity-dependent techniques. The VONDS may be useful in meeting these criteria.

\section{Literature Cited}

Dreschel, T.W. and J.C. Sager. 1989. Control of water and nutrients using a porous tube: A method for growing plants in space. HortScience 24(6):944-947.

Kitaya, Y., T. Imanaka, M. Kiyota, and I. Aiga. 1988. Advantageous arrangement of plants in a plant factory-Cultivation of lettuce upside down. Acta Hort. 230:271-278.

Morrow, R.C., W.R. Dinauer, R.J. Bula, and T.W. Tibbitts. 1990. Astroculture-1, a middeck flight experiment to evaluate nutrient delivery in microgravity. Amer. Soc. Gravitational \& Space Biol. Bul. 4(1):49. (Abstr.)

Wheeler, R.M., C.L. Mackowiak, and J.C. Sager. 1991. Soybean stem growth under high-pres- 
sure sodium with supplemental blue lighting. Agron. J. 83:903-906.
Wright, B.D., W.C. Bausch, and W.M. Knott. 1988. A hydroponic system for microgravity plant experiments. Trans. Amer. Soc. Agr. Eng. 31:440-446. 